\title{
A história da ciência no ensino de física e a vigilância epistemológica
}

\author{
Elio Carlos Ricardo ${ }^{1,2}$
}

(1) Universidade de São Paulo, Faculdade de Educação, Avenida das Universidades 308, Butantã 05508-900, São Paulo, Brasil. E-mail: elioricardo@usp.br

(2) Universidade de Salamanca, Instituto de Estudos da Ciência e da Tecnologia, Doutorado em Lógica e Filosofia da Ciência, Calle Espejo 2, 37007, Salamanca, Espanha.

Ricardo E.C. (2020) A história da ciência no ensino de física e a vigilância epistemológica. Pesquisa e Ensino em Ciências Exatas e da Natureza, 4: e1506. http://dx.doi.org/10.29215/pecen.v4i0.1506

Editora acadêmica: Thatyara Freire de Souza. Recebido: 09 junho 2020. Aceito: 17 setembro 2020. Publicado: 25 setembro 2020.

Resumo: Há várias maneiras de considerar a relação entre a história da ciência e a didática da ciência. Além disso, a teoria da Transposição Didática proposta por Yves Chevallard mostrou as transformações que o conhecimento científico sofre para se tornar um saber ensinado na sala de aula. Porém, ambos ainda são difíceis de serem aplicados pelo professor. Este artigo sugere a vigilância epistemológica como uma ferramenta didática para produzir conteúdos mais significativos no contexto escolar. Nesse caso, a história da ciência é uma importante referência. Para ilustrar esses argumentos, é apresentado um exemplo da mecânica.

Palavras chave: história da ciência, ensino de física, transposição didática, vigilância epistemológica.

\section{History of science in physics teaching and the epistemological vigilance}

Abstract: There are many ways to consider the relationship between history of science and didactic of science. Besides, Didactic Transposition Theory proposed by Yves Chevallard showed the transformations scientific knowledge suffers to become taught knowledge in the classroom. However, both of them are still difficult to be applied by teachers. This paper suggests the epistemological vigilance as a didactic tool to produce contents more significant to the school context. In this case, history of science is an important reference. To illustrate these arguments, it is presented an example of mechanics.

Key words: history of science, physics teaching, didactic transposition, epistemological vigilance.

\section{Introdução}

A relação entre a história das ciências e a didática das ciências pode ser compreendida de diversas maneiras, conforme mostram algumas pesquisas relacionadas ao tema (Matthews 1995; Kapitango 2011; Höttecke et al. 2012; Teixeira et al. 2012; Silva et al. 2018). Influenciados, em parte, pela epistemologia histórica de Gaston Bachelard e sua concepção de obstáculos epistemológicos, as estruturas de raciocínio dos alunos ao aprenderem ciência tornaram-se objetos de investigação (Viennot 1977, 1979; Saltiel 1978). Na mesma época, pesquisas relacionadas às concepções alternativas dos alunos frente aos conceitos científicos ganharam força (Driver \& Easley 1978; Gilbert et al. 1982; Gilbert 1983).

Essas pesquisas ajudaram a destacar a relevância da história da ciência para compreender questões relativas ao seu ensino. Raichvarg (1987: 3) ressalta que "a questão das relações entre a construção histórica e a construção pessoal dos conhecimentos deve necessariamente constituir um campo de investigaçôes para a didática”. Entretanto, o autor 
alerta que, ao mesmo tempo em que ambos estão relacionados à ideia de um progresso, uma evolução, é uma relação entre campos e períodos distintos e deveria, portanto, ser estabelecida com cautela. Por exemplo, uma analogia apressada entre a noção de impetus e as concepções alternativas dos alunos (Zylbersztajn 1983) poderia desconsiderar as diferenças entre o ambiente científico e o não-científico e, por isso, conduzir a modelos didáticos inconsistentes. Nas instituições de ensino, o que se espera é a construção pessoal do conhecimento a partir de um conjunto de saberes socializados, presentes nos materiais didáticos, nos programas, nas ementas. Nesse sentido, Raichvarg (1987: 28) sugere outra questão: "como se constrói um saber socializado que vai servir de base para a construção de um segundo saber?”. Esses distintos saberes empregariam as mesmas estruturas cognitivas? Ou, a forma como são estruturados e apresentados tais saberes socializados interferem em sua apropriação? Essa última questão será o objeto de reflexão neste trabalho.

\section{A construção do conhecimento}

Uma resposta para as questões acima, em especial as primeiras, consiste em uma das hipóteses da epistemologia de Piaget, conforme ressaltam Raichvarg (1987), Rosmorduc (1987) e Matthews (1995). Entretanto, essa aproximação entre a construção histórica da ciência e as concepções subjetivas é pouco clara e, de acordo com Raichvarg (1987), isso se deve, entre outras razões, ao fato de que Piaget teria tomado como referência a ciência estática, ou seja, aquela ciência já estabelecida como tal, negligenciando o que estaria envolvido para além dos resultados dessa ciência.

Aqui caberia estabelecer uma diferença inicial entre saberes e conhecimento. Os primeiros caracterizam uma representação padronizada do mundo, enquanto que o segundo se refere a uma representação subjetiva do mundo e, portanto, não necessariamente padronizada. Ambos podem ser satisfatórios nas relações cotidianas do sujeito com o mundo, o que poderia justificar a resistência dos obstáculos epistemológicos e das concepções alternativas. As instituições de ensino visam a modificar e/ou ampliar esses saberes e conhecimentos nos alunos. Mas, existe a possibilidade de uma co-habitação de diferentes concepções e, conforme salientam Johsua \& Dupin (1993: 128), "pode-se reconhecer como uma autêntica progressão cognitiva a simples ampliação da classe de situações abordáveis com uma concepção", o que poderia prejudicar os propósitos iniciais de ensino. Ao tratar das dificuldades de aprendizagem dos alunos, Matthews (1995: 183) recorre a exemplos da mecânica para afirmar que "há uma diferença entre os objetos do mundo real e os objetos teóricos da ciência. Confundir os primeiros com os últimos é confundir a ciência aristotélica com a newtoniana", o que evidencia os riscos em negligenciar ou minimizar as rupturas epistemológicas entre a ciência, o senso comum e o mundo real.

Por outro lado, Zylbersztajn (1983), Martins (1988), Zanetic (1988), Zylbersztajn \& Assis (1999), Harres (2002), entre outros, ressaltam que muitas concepções dos alunos a respeito dos saberes científicos têm similaridade com ideias que já fizeram parte do discurso científico. Um conhecimento da história pode assegurar que essa relação não seja forçada e que possa levar os professores a compreenderem melhor os conceitos que pretendem ensinar e, segundo Martins (1988), também respeitarem as dúvidas dos alunos, explorando-as didaticamente. Com isso, não se pretende reduzir o uso da história a apenas uma dimensão psicológica, no sentido de enfrentar dificuldades de aprendizagem, mas de tentar entender sob quais perspectivas os alunos pensam daquele modo e os levam à incompreensão de determinado assunto. Nesse sentido, Delizoicov (1991) apresenta uma questão relevante ao tratar das pesquisas acerca das concepções alternativas:

Acredito que a pergunta formulada por esses pesquisadores - "quais os conceitos que os alunos têm sobre o conceito científico x?” - deve ser precedida (ou no mínimo articulada) pelas perguntas: que necessidade(s) levou(aram) os alunos a conceberem tal conceito? O que os alunos querem "explicar com os conceitos que estão usando?” (Delizoicov 1991: 124). 
Isso vai muito além de uma relação superficial entre a ciência precedente e as concepções alternativas dos alunos. Ademais, Astolfi (1988) destaca que os obstáculos à aprendizagem podem se encontrar no campo linguístico, lógico ou epistemológico e têm um "núcleo duro" resistente a mudanças. Assim, torna-se inevitável lembrar de Gaston Bachelard, ao afirmar que:

\footnotetext{
É para problematizar o conhecimento já construído pelo aluno que ele deve ser apreendido pelo professor; para aguçar as contradições e localizar as limitações desse conhecimento, quando cotejado com o conhecimento científico, com a finalidade de propiciar um distanciamento crítico do educando ao se defrontar com o conhecimento que ele já possui e, ao mesmo tempo, propiciar a alternativa de apreensão do conhecimento científico (Bachelard 1977: 132).
}

Todavia, a forma como a física é apresentada aos alunos parece distanciar-se desses propósitos. Para Robilota (1988), mesmo quando se dominam os conteúdos específicos da física, mas sem compreender suas origens, há, frequentemente, uma abordagem autoritária do seu ensino, como se este se justificasse por si mesmo. Isso, ainda segundo Robilota (1988), faz com que a física não seja compreendida em seu conjunto, em sua estrutura como uma disciplina, permitindo que ela tenha sentido e seja inteligível internamente. Mas, destaca o autor, "conduzir um estudante que está fora da estrutura para dentro dela é um processo altamente complexo, que demanda do professor uma razoável compreensão de como a ciência se desenvolve e evolui" (Robilota 1988: 15). Essa "perda de sentido" da física ensinada será tratada mais adiante.

Além disso, tanto Robilota (1988) quanto Zylbersztajn \& Assis (1999) ressaltam que alguns conceitos são tratados como óbvios e apontam exemplos da mecânica, a saber, referenciais inerciais, espaço contínuo, tempo contínuo e absoluto, forças fictícias, entre outros, ignorando-se o confronto de ideias e o contexto em que tais teorias e modelos se desenvolveram. Isso reduz, ou mesmo elimina, o senso crítico dos alunos e suas dúvidas são tratadas como descabidas e inconsistentes. Na mesma direção, Martins (1988) apresenta outro exemplo em relação ao sentido de circulação de um campo magnético em torno de um fio por onde passa uma corrente elétrica como sendo dado pela "regra da mão direita". Quando se recorre a explicações do tipo "é uma convenção”, ou "porque explica o fenômeno", utiliza-se o recurso autoritário e ignora-se o problema conceitual de simetria, destaca o autor. Os caminhos para se chegar às teorias conhecidas são desprezados e uma visão distorcida da ciência acaba prevalecendo: a de que é tão linear e sem contradições quanto aparece nos manuais (livros de graduação) e livros didáticos (educação básica). Trata-se de uma incompreensão da construção da ciência física.

Ademais, conforme Rosmorduc (1987), a ciência nasce de uma junção entre curiosidade, necessidades, regularidades, explicações, hipóteses e experiências no contexto de uma determinada sociedade. Há, frequentemente, uma tendência em avaliar e/ou apresentar a ciência passada com as perspectivas atuais. Isso faz com que os saberes anteriores sejam tratados como grosseiros ou mesmo ingênuos. Desse modo, a história da ciência permitiria sua contextualização, que pode ser compreendida tanto em sentido amplo quanto em sentido restrito, ou externo e interno.

Em seu sentido amplo, ou externo, a contextualização via abordagem histórica buscaria justamente localizar a construção de determinados saberes no seio de uma sociedade, com suas expectativas, interesses e instrumentos cognitivos e teóricos. Basta lembrar que alguns avanços científicos tiveram que aguardar a criação de aparatos técnicos. As bombas de vácuo servem de exemplo. Uma abordagem histórica interna ocupa-se, primordialmente, do desenvolvimento dos conceitos e das ideias de uma determinada teoria estabelecida. Por vezes, é chamada de história conceitual da ciência. No entanto, essa divisão parece excessivamente artificial, pois as abordagens acerca da história da ciência podem se dar de vários modos, desde uma visão mais sociológica e/ou antropológica a uma perspectiva que parte do interior do conjunto de conceitos, modelos, pressupostos ontológicos e gnosiológicos presentes em determinado período envolvendo a construção de uma teoria. Tanto uma quanto outra podem se ocupar de curtos 
períodos, bem definidos e localizados, caracterizando um estudo de caso, ou ampliar-se para uma escala temporal maior.

Entretanto, o uso da história da ciência como elemento contextualizador encontra defensores e opositores. Matthews (1995) já sintetizou alguns desses confrontos. Para o autor, algumas posições contrárias se apoiam nos supostos benefícios de uma educação conformista em ciências defendida por Thomas Kuhn, o que se aplicaria à formação de cientistas e não necessariamente de professores de ciências/física. Por outro lado, ao mesmo tempo em que alerta para os riscos dos conceitos serem tomados com a visão contemporânea, Matthews (1995) destaca que os significados e os sentidos das palavras dependem do contexto em que foram aplicados originalmente, modificando-se ao longo do tempo. Assim, a história poderia auxiliar na compreensão dos conceitos científicos. Essa possível contribuição se aproxima dos objetivos do presente trabalho, ao mesmo tempo em que é preciso considerar que não seria qualquer história que levaria aos propósitos formativos esperados, pois também será o resultado de uma nova estruturação, a partir de determinadas escolhas. Assim como os saberes a ensinar, a história poderá ser apresentada sob distintas perspectivas e também sairá do seu contexto original. Forato (2009) e Forato et al. (2012) já trataram dos desafios que isso implica.

\section{A didatização dos saberes escolares}

Os processos de didatização dos conteúdos escolares envolvem um conjunto complexo de variáveis que vão além da mera simplificação da ciência de referência. Além disso, essa passagem não é linear, ao contrário, sofre influências de distintas esferas sociais e responde, ao menos em tese, a um projeto de formação definido em algum momento. Dito de outro modo: de onde vem aquilo que ensinamos na escola? Quem decide o que deve e o que não deve ser ensinado?

Uma teoria que procura esclarecer esse fenômeno didático foi proposta originalmente por Yves Chevallard, matemático francês que se propôs a investigar as relações entre o saber ensinado na sala de aula e o saber sábio, aquele produzido pelos cientistas. Para esse autor, a Transposição Didática consiste em uma ferramenta teórica que permite, à didática e ao professor, "tomar distância, interrogar as evidências, por em questão as ideias simples, desprender-se da familiaridade enganosa de seu objeto de estudo. Em uma palavra, o que permite exercer sua vigilância epistemológica" (Chevallard 1991: 16). Conforme Chevallard, quando uma determinada fração de um saber de referência é eleita para ser ensinada, sofrerá necessariamente algumas simplificações e modificações para se tornar ensinável.

Isso se torna mais evidente quando Chevallard (1991: 18) afirma que "o saber produzido pela transposição didática será, portanto, um saber exilado de suas origens e separado de sua produção histórica na esfera do saber sábio, legitimando-se como saber ensinado, como algo que não é de nenhum tempo nem de nenhum lugar". Contudo, a didatização é uma exigência incontornável e, por isso, torna-se fundamental a compreensão desse processo para que se possa organizá-la em função do projeto social de ensino que se deseja. A rigor, o professor trabalha no interior da Transposição Didática, uma vez que sua atuação ocorre no interior de um sistema de ensino no qual muitas decisões já foram tomadas e escolhas já foram feitas. Esse jogo de influências e interesses ocorre dentro de um nicho social mais amplo, o qual Chevallard chama de noosfera. Assim, o primeiro passo seria reconhecer que há essa transposição, pois os funcionamentos institucionais são distintos entre a esfera da produção dos saberes e seu ensino e, um segundo passo, seria admitir que há possibilidades de organizar os saberes didatizados de diferentes modos. Ou seja, trabalhar na Transposição Didática.

Mas, a recepção hostil à ideia da Transposição Didática tem outro motivo: coloca em xeque a legitimidade dos conteúdos ensinados na escola frente à ciência que lhes deu origem. Desse modo, quando um aluno pergunta o porquê de aprender física na escola, por exemplo, parece que ele estaria questionando a ciência e não seu ensino. Essa pergunta é tratada, muitas vezes, como descabida e é respondida fazendo-se referência à ciência física e não ao seu ensino. Ricardo \& Freire (2007) mostraram que a maioria dos alunos do nível médio reconhece a 
importância da ciência, mas questiona a presença da disciplina de física na escola. Constatadas as diferenças entre a física escolar e a física dos físicos, a credibilidade assegurada pela legitimidade epistemológica atribuída a esta não é transferida àquela. Ou seja, quando é revelado que não é a ciência física que está na escola, parece haver uma denúncia que abala a tranquilidade da relação didática. Nas palavras de Chevallard (1994: 146), "nenhum saber ensinado se autoriza por si mesmo". A física escolar carece de uma legitimação cultural.

Determinadas partes da ciência serão escolhidas para serem ensinadas, a partir disso sofrerão um conjunto de adaptações e transformações para se tornarem objetos de ensino (Chevallard 1991). Trata-se, portanto, de um novo saber que fará parte dos programas de formação. Assim, não se poderia atribuir à Transposição Didática os problemas no ensino. É um trabalho necessário para tornar determinado saber ensinável. Para isso, Chevallard destaca que devem ocorrer alguns processos bem demarcados, tais como: a textualização, a despersonalização, a desincretização e a descontextualização, entre outros.

A textualização dos saberes é uma exigência para sua explicitação, a fim de permitir sua adequação temporal e controle social. Essa textualização garante, portanto, uma programabilidade da aquisição dos saberes e de sua exposição nos livros didáticos e outros materiais. Esse novo encadeamento racional pode levar a inversões ou a reorganizações cronológicas. Veja-se, por exemplo, a forma como o eletromagnetismo é organizado nos livros e manuais; inicia-se pela definição de carga elétrica e, a partir desse conceito, decorrerá toda a sequência de apresentação dos conteúdos. Todavia, esse conceito é historicamente posterior à maioria dos conceitos e teorias que serão trabalhadas.

Outra consequência dessa textualização é a exclusão do trabalho coletivo da ciência, permeada por tensões e controvérsias, transmitindo-se a ideia de descobertas geniais e isoladas. As teorias científicas assumem status de leis (Lei de Coulomb, Lei de Ohm etc.) reduzidas a fórmulas matemáticas, como se tivessem sido propostas exatamente desse modo pelos cientistas. Trata-se de um processo de despersonalização.

Outro processo identificado por Chevallard é a desincretização, que consiste na delimitação de campos de saberes, o que resulta na especialização e nas divisões em disciplinas escolares, em capítulos e seções. Ao mesmo tempo em que é uma exigência da organização escolar, pode criar a falsa ideia de que é a única sequência possível de apresentação dos conteúdos a ensinar. Um exemplo ilustrativo dessa delimitação e separação de campos de saberes é o conceito de energia e sua conservação, tratado na mecânica e na termodinâmica, muitas vezes entendido pelos alunos como sendo coisas diferentes. Outro exemplo ocorre na disciplina de química do ensino médio: no primeiro e no segundo ano, muitos conteúdos são oriundos de pesquisas em física (modelos atômicos, ligações químicas, transformações gasosas etc.).

Para atender às exigências de um determinado projeto didático, os saberes a ensinar são estruturados em uma ordem lógica apoiada em pré-requisitos, os quais omitem a dinâmica da construção da ciência. Os investimentos pessoais de cada um dos atores envolvidos, bem como as contribuições anteriores à justificação da teoria, desaparecem, reforçando a despersonalização dos saberes a ensinar já mencionada anteriormente.

Finalmente, haverá uma descontextualização relativa aos saberes de referência; um exílio de sua origem histórica, para ser recontextualizado na forma discursiva de um saber a ensinar. Portanto, a descontextualização desses saberes faz com que ocorra uma "desarticulação da rede de problemáticas e problemas que outorgam seu sentido completo" (Chevallard 1991: 71). Além disso, segundo o autor, "o processo de ensino difere fundamentalmente do processo de pesquisa: no primeiro, os problemas não são o motor de progressão" (Chevallard 1991: 76). Uma consequência disso é a estruturação do ensino a partir de respostas a perguntas que os alunos não fizeram. Desse modo, não deveria causar tanta estranheza o pouco sentido que os alunos veem nas aulas de física, conforme mostram Ricardo \& Freire (2007).

Até aqui se poderia dizer que uma análise epistemológica chegaria a resultados semelhantes aos alcançados pela Transposição Didática. No entanto, o próprio Chevallard salienta que as epistemologias convencionais se ocupam da produção dos saberes de referência, 
enquanto que sua teoria busca compreender como os saberes ensinados chegam nas instituições de ensino. Além disso, os saberes didatizados também necessitam de uma legitimação epistemológica, ou seja, não se pode propor como objeto de ensino um conceito completamente desconectado de sua referência. Mas, exigir-se-á também uma legitimação cultural compatível com um projeto de formação, ao menos em tese, pois há uma seleção do que se ensina e do que não se ensina.

Essa visão sociológica dos saberes e a suposição de uma única referência dos saberes escolares custaram algumas críticas a Chevallard (Caillot 1996; Johsua 1997). O "isolamento" sociológico poderia negligenciar a natureza da ciência e reduzir a investigação de seu objeto ao estudo de um fenômeno social. Nesse caso, o objeto "saber sábio" seria definido sociologicamente e transformado em um discurso, o que parece ser indesejado (Ricardo 2005).

Todavia, a Transposição Didática de Chevallard, ao revelar a existência desse processo complexo de textualização dos saberes a ensinar, possibilita uma vigilância epistemológica daquilo que se ensina em relação àquilo que foi assumido como projeto de ensino e torna mais claras as diferenças entre as instâncias de saberes. Além disso, as instituições de ensino impõem certa rotina às práticas docentes, reforçada pelos objetivos de uma formação geral supondo-se uma homogeneidade entre os alunos. Entretanto, ao mesmo tempo em que a textualização dos saberes assegura sua programabilidade e, com isso, uma adequação a um tempo formal, sobrepõe-se aos tempos de aprendizagem (individuais). Possíveis desvios desse tempo de aprendizagem abstrato são frequentemente minimizados pela abordagem predominantemente operacional da física, reduzida, muitas vezes, à resolução de problemas, sem uma discussão conceitual.

\section{O exemplo da mecânica}

As chamadas leis de Newton são apresentadas nos manuais e livros didáticos de maneira bastante simplificada, frequentemente reduzidas ao enunciado das três leis seguidas de algumas aplicações para a resolução de problemas padrão. Pode-se dizer que o mesmo ocorre com a gravitação, especialmente no ensino médio. Há manuais inclusive que afirmam ser a primeira lei um caso particular da segunda lei, se a força resultante for nula. Essa é uma visão meramente operacional da expressão matemática da segunda lei. Os aspectos conceituais, ou semânticos, são ignorados.

A maior parte do conteúdo de física apresentado nos manuais se reduz a uma estrutura operacional, ou seja, são fórmulas para resolver problemas. Além de excluir os aspectos conceituais da física, tal abordagem negligencia sua construção histórica. Parece que toda a contribuição de Newton para a mecânica foi enunciar suas três leis, do nada; ou que a mecânica estudada é uma síntese daquela apresentada no livro Princípios Matemáticos da Filosofia Natural (Philosophiae Naturalis Principia Mathematica, geralmente identificado por Principia). Ademais, quem procurar a expressão $F=m a$ nesta obra, não a encontrará e tampouco seria correto afirmar que a mecânica textualizada nos manuais e livros didáticos consiste na aplicação do cálculo de Leibniz à mecânica de Newton. A rigor, nem mesmo a chamada mecânica newtoniana corresponde à mecânica de Newton! As contribuições de D'Alembert, Euler, Lagrange, entre outros, são desconsideradas (Ricardo 2012).

Conforme Blay (1995), o trabalho de Newton nos Principia se caracteriza não apenas pela organização dedutiva de sua mecânica racional, mas também pela síntese de trabalhos anteriores, como os de Galileu e Huygens, e da exposição de novos conceitos que possibilitaram construir uma ciência matemática dos movimentos. De fato, além de Galileu e Huygens, também Hooke, Descartes, Kepler, entre outros nomes, são citados nas páginas dos Principia. Blay (1995, 2002) e Grant (1995) ressaltam inclusive que é possível identificar historicamente um manuscrito precursor da obra final.

Após uma visita que Edmund Halley fez a Newton em Cambridge no ano de 1684, questionando-o sobre qual seria a curva descrita pelos planetas supondo uma força de atração em direção ao Sol inversamente proporcional ao quadrado da distância entre eles, Newton teria 
respondido imediatamente que se tratava de uma elipse e, mais ainda, que a teria calculado. Como Newton não teria encontrado seus cálculos na ocasião, comprometeu-se a refazê-los e enviar a Halley, o que ocorreu cerca de três meses depois (Cohen \& Westfall 2002; Panza 2003).

Halley recebeu um pequeno tratado sobre gravitação, cujo título era De Motu. Grant (1995) afirma que tal manuscrito teria sido escrito entre 1665 a 1670 com cerca de 25 páginas. Destaca ainda que o original enviado a Halley se perdeu, mas que há várias cópias ou versões nas bibliotecas de Cambridge e Londres. Ainda nos anos de 1684 e 1685 Newton registra para seus cursos em Cambridge o manuscrito intitulado "Lucasian Lectures de Motu Corporum", o que seria, segundo Grant (1995), um intermediário entre o De Motu e a versão dos Principia apresentado para publicação na Royal Society.

Vale lembrar que desde a publicação da primeira edição dos Principia em 1687 à publicação do Mécanique Analitique de Lagrange em 1788, passaram-se 101 anos! No Prefácio da primeira edição dos Principia, Newton exalta a geometria e afirma o seguinte: "a geometria fundamenta-se na prática mecânica e é nada mais que aquela parte da mecânica universal que reduz a arte de medir a proposições exatas e a demonstrações" (Newton 1687). No Prefácio do Mécanique, com certo entusiasmo, Lagrange afirma: "não se encontrará figuras nesta obra. Os métodos que eu exponho não demandam nem construções nem raciocínios geométricos ou mecânicos, mas somente operações algébricas...” (Lagrange 1788). Consolida-se, portanto, a álgebra como estrutura de pensamento na ciência dos movimentos em detrimento da geometria. A anedota da maçã caindo na cabeça de Newton, levando-o a ter ideias geniais que resultaram nos Principia, parece cada vez menos plausível. A ideia de um trabalho coletivo ao longo de muitos anos torna-se mais aceitável.

\section{Considerações finais}

Essa breve exposição de alguns aspectos históricos envolvendo a mecânica de Newton evidencia os processos de textualização, desincretização, despersonalização e descontextualização propostos por Chevallard. No entanto, todos esses processos ocorrem conjuntamente e suas denominações servem para identificá-los mais nitidamente. A textualização fica evidente quando se verifica que toda a mecânica de Newton se reduz praticamente à apresentação das três leis e de problemas de aplicação da relação $F=m a$, com sua variante $P=m g$. A descontextualização também se manifesta em vários momentos, notadamente quando o problema original que levou Newton a publicar os Principia não é tratado nos livros didáticos, bem como o que já se sabia na época. Uma desincretização ocorre quando se "traduz" a segunda lei de Newton em sua versão algébrica $F=m a$, portanto, posterior; ou quando as leis de Newton e a Gravitação são tratadas em capítulos distintos nos livros. A despersonalização é clara quando personagens importantes na construção da mecânica ficam de fora da versão didatizada, a saber, D’Alembert, Euler, Lagrange, Varignon e outros. Ao mesmo tempo, a despersonalização concentra os créditos em um único personagem, nesse caso, Newton, para emprestar um critério de autoridade e legitimidade aos conteúdos escolares.

Entretanto, alguns desses problemas não são novos. No final do livro L'Évolution de la Mécanique de Pierre Duhem (1903), há uma resenha analítica do livro Mechanik de Ernst Mach. Duhem conclui sua análise dizendo o seguinte:

Este livro [Mechanik] foi escrito para impedir que a Mecânica se degenere em uma sequência de fórmulas exatas e precisas, mas secas e estéreis. No ensino francês, por causas que são inúteis enumerar, pois todos as conhecem, a Mecânica, pouco a pouco esvaziada de todo conteúdo real, encontra-se reduzida a uma forma rígida, mas morta; (...) que os professores e estudantes leiam e meditem a Mecânica do professor Mach; eles encontrarão os princípios de ressurreição que, sobre as ossadas dessecadas desse esqueleto, farão renascer a carne, viva e palpitante (Duhem 1903: 462).

A partir das reflexões aqui apresentadas, espera-se que o exercício da vigilância epistemológica pelos professores e o recurso didático da história da ciência possa dar vida a esses 
ossos secos que se tornou a mecânica. Evidencia-se, assim, que não existe um único caminho possível para a didatização dos conteúdos escolares e que outras formas de apresentá-los e ensiná-los podem contribuir para sua apropriação pelos alunos.

\section{Referências}

Astolfi J. (1988) El Aprendizaje de Conceptos Científicos: aspectos epistemológicos, cognitivos y linguísticos. Enseñanza de las Ciencias, 6(2): 147-155.

Bachelard G. (1977) O racionalismo aplicado. Tradução de Nathanael Caixeiro. Rio de Janeiro: Zahar. $221 \mathrm{p}$.

Blay M. (1995) Les “Principia” de Newton. Paris: Presses Universitaires de France. 247 p.

Blay M. (2002) La Science du Mouvement: de Galilée à Lagrange. Paris: Éditions Belin. 326p.

Caillot M. (1996) La théorie de la transposition didactique est-elle transposable? In: Raisky C. \& Caillot M. (éds). Au-delà des didactiques, le didactique: débats autour de concepts fédérateurs. Buxelles: De Boeck \& Larcier. 214 p.

Chevallard Y. (1991) La transposición didáctica: del saber sábio al saber enseñado. Buenos Aires: Aique Grupo Editorial. 241 p.

Chevallard Y. (1994) Les processus de transposition didactique e leur théorisation. In: Arsac G., Chevallard Y., Martinand J.-L. \& Tiberghien A. (Orgs). La Transposition Didactique à l'Épreuve. Paris: La Pensée Sauvage. 321 p.

Cohen B. \& Westfall R. (2002) Newton: textos, antecedentes, comentários. Tradução Vera Ribeiro. Rio de Janeiro: Contraponto. 524 p.

Delizoicov D. (1991) Conhecimento, Tensões e Transições. Tese (Programa de Pós-Graduação em Educação). Universidade de São Paulo, São Paulo.

Driver R. \& Easley J. (1978) Pupils and paradigms: a review of literature related to concept development in adolescent science students. Studies in Science Education, 5(1): 61-84.

Duhem P. (1903) L’Évolution de la Mécanique. Paris: Vrin (1992). 473 p.

Forato T. (2009) A Natureza da Ciência como Saber Escolar: um estudo de caso a partir da história da luz. Tese (Programa de Pós-Graduação em Educação). Universidade de São Paulo, São Paulo.

Forato T., Martins R. \& Pietrocola M. (2012) History and Nature of Science in High School: building up parameters to guide educational materials and strategies. Science \& Education, 21: 657-682. https://doi.org/10.1007/s11191-011-9419-3

Gilbert J. (1983) Alternative conceptions: which way now? New York: AAPT Winter Meeting.

Gilbert J., Osborne R. \& Fensham P. (1982) Children's science and its consequences for teaching. Science Education, 66(4): 57-73. https://doi.org/10.1002/sce.3730660412

Grant F. (1995) De la Gravitation et du Mouvement. Paris: Gallimard. 112 p.

Harres J.B. (2002) Desenvolvimento histórico da dinâmica: referente para a evolução das concepções dos estudantes sobre força e movimento. Revista Brasileira de Pesquisa em Educação. 2(2): 89-101.

Höttecke D., Henke A. \& Riess F. (2012) Implementing History and Philosophy in Science Teaching: strategies, methods, results and experiences from the European HIPST Project. Science \& Education, 21(9): 1233-1261. https://doi.org/10.1007/s11191-010-9330-3

Johsua S. (1997) Le concept de Transposition Didactique peut-il étendre sa portée au delà de la didactique des sciences et des mathématiques? Skholê, 6: 21-35.

Johsua S. \& Dupin J. (1993) Introdution à la didactique des sciences et des mathématiques. Paris: Presses Universitaires de France. 234 p.

Kapitango K. (2011) História e Filosofia da Ciência no Ensino de Ciências Naturais: o consenso e as perspectivas a partir de documentos oficiais, pesquisas e visão dos formadores. Tese (Programa de Pós-Graduação em Educação). Universidade de São Paulo, São Paulo.

Lagrange J-L. (1788) Mécanique Analytique. Paris: Éditions Jacques Gabay. 512 p. 
Martins R. (1988) Contribuições do Conhecimento Histórico ao Ensino do Eletromagnetismo. Caderno Catarinense de Ensino de Física, 5(número especial): 49-57.

Matthews M. (1995) História, Filosofia e Ensino de Ciências: a tendência atual de reaproximação. Caderno Catarinense de Ensino de Física, 12(3): 164-214. https://doi.org/10.5007/\%25x

Newton I. (1687) Philosophiae Naturalis Principia Mathematica (Princípios Matemáticos da Filosofia Natural) (2010). Tradução J. Resina Rodrigues. Lisboa: Fundação Calouste Gulbenkian. 980 p.

Panza M. (2003) Newton. Paris: Les Belles Lettres. 270 p.

Raichvarg D. (1987) La didactique a-t-elle raison de s'interesser a l'histoire des sciences? Aster, 5: $3-34$.

Ricardo E. (2005) Competências, Interdisciplinaridade e Contextualização: dos Parâmetros Curriculares Nacionais a uma compreensão para o ensino das ciências. Tese (Programa de Pós-Graduação em Educação Científica e Tecnológica). Universidade Federal de Santa Catarina, Florianópolis, Santa Catarina.

Ricardo E. (2012) Elementos Físicos e Matemáticos da Mecânica Analítica, a Relação entre as Duas Ciências e a Vigilância Epistemológica. Tese (Livre-Docência em Ensino de Ciências e Matemática). Universidade de São Paulo, São Paulo.

Ricardo E. \& Freire J. (2007) A Concepção dos Alunos sobre a Física do Ensino Médio: um estudo exploratório. Revista Brasileira de Ensino de Física, 29(2): 251-266. https://doi.org/10.1590/S1806-11172007000200010

Robilota M. (1988) O Cinza, o Branco e o Preto: da relevância da história da ciência no ensino de física. Caderno Catarinense de Ensino de Física, 5(número especial): 7-22.

Rosmorduc J. (1987) L'Histoire de la Physyque Peut-Elle Aclairer les Obstacles Epistemologiques? Aster, 5(3): 117-143.

Saltiel E. (1978) Concepts cinematiques et raisonnements naturels: étude de la comprehension de changements de referentiels galiléens par les étudiants en science. Thèse d'État. Université Paris 7 - Diderot, Paris.

Silva E., Teixeira E. \& Penido M. (2018) Análise de Propostas Didáticas Orientadas por Abordagens Históricas. Caderno Brasileiro de Ensino de Física, 35(3): 766-804.

Teixeira E., Greca I. \& Freire O. (2012) The History and Philosophy of Science in Physics Teaching: a research synthesis of didactic intervention. Science \& Education, 21(6): 771-796. https://doi.org/10.1007/s11191-009-9217-3

Viennot L. (1977) Le raisonnement naturel en dynamique élemenaire. Thèse d’État. Université Paris 7 - Diderot, Paris.

Viennot L. (1979) Spontaneous reasoning in elementary dynamics. European Journal of Science Education, 1(2): 67-91.

Zanetic J. (1988) Dos "Principia" da Mecânica aos "Principia" de Newton. Caderno Catarinense de Ensino de Física, 5(número especial): 23-35.

Zylbersztajn A. (1983) Concepções espontâneas em física: exemplos em dinâmica e implicações para o ensino. Revista de Ensino de Física, 5(2): 3-16.

Zylbersztajn A. \& Assis A. (1999) Sobre a Possível Realidade das Forças Fictícias: uma visão relacional da mecânica. Acta Scientiarum, 21(4): 817-822.

https://doi.org/10.4025/actascitechnol.v21i0.3078 